\title{
https://helda.helsinki.fi
}

\section{Nordic EPOS - A FAIR Nordic EPOS Data Hub}

\section{Korja, Annakaisa}

Institute of Seismology, University of Helsinki 2021

Korja , A , Atakan , K, Voss , P H, Roth , M , Vogfjord, K, Kozlovskaya , E , Tanskanen , E \& Junno , N 2021, Nordic EPOS - A FAIR Nordic EPOS Data Hub . in I Kukkonen , T Veikkolainen, S Heinonen , F Karell , E Kozlovskaya , A Luttinen , K Nikkilä , V Nykänen , M Poutanen , P Skyttä , E Tanskanen \& T Tiira (eds), LITHOSPHERE 2021: ELEVENTH SYMPOSIUM ON STRUCTURE, COMPOSITION AND EVOLUTION OF THE LITHOSPHERE : PROGRAMME AND EXTENDED ABSTRACTS . vol. 71 , Report S , vol. 71 , Institute of Seismology, University of Helsinki , Helsinki , pp. 63-64, Lithosphere 2021 , Finland , 19/01/2021.< https://www.seismo.helsinki.fi/ilp/lito2021/Lithosphere_2021_Symposium_Abstract_Volume.pdf $>$

http://hdl.handle.net/10138/333250

publishedVersion

Downloaded from Helda, University of Helsinki institutional repository.

This is an electronic reprint of the original article.

This reprint may differ from the original in pagination and typographic detail.

Please cite the original version. 


\title{
Nordic EPOS - A FAIR Nordic EPOS Data Hub
}

\author{
A. Korja ${ }^{1}$, K. Atakan ${ }^{2}$, P.H. Voss ${ }^{3}$, M. Roth ${ }^{4}$, K. Vogfjord ${ }^{5}$, E. Kozlovskaya ${ }^{6}$, E.I. Tanskanen ${ }^{7}$, \\ N. Junno ${ }^{1}$ and Nordic EPOS Working Group ${ }^{2}$ \\ ${ }^{1}$ Department of Geosciences and Geography, P.O. Box 64, FIN-00014 University of Helsinki \\ ${ }^{2}$ University of Bergen \\ ${ }^{3}$ Geological Survey of Denmark and Greenland (GEUS) \\ ${ }^{4}$ Uppsala University \\ ${ }^{5}$ Icelandic Meteorological Office (IMO) \\ ${ }^{6}$ Oulu Mining School, University of Oulu \\ ${ }^{7}$ Sodankylä Geophysical Observatory, University of Oulu \\ E-mail: Annakaisa.korja@helsinki.fi
}

Nordic EPOS - A FAIR Nordic EPOS Data Hub - is a consortium of the Nordic geophysical observatories delivering on-line data to EPOS Thematic Core Services. It will promote common Nordic interests in EPOS, and promote and build data services beneficial for the Nordic community. It will offer joint workshops and training in FAIR data collection, usage and management in monitoring of seismicity and induced seismicity, ash and gas eruptions, geomagnetic hazards. It will also disseminate related tutorials, demos and actual and virtual training sessions.

Keywords: EPOS (European Plate Observing System), Nordic countries, collaboration, FAIR (Findable, Accessible, Interoperable and Re-usable), data

\section{Overview}

Many of the grand challenges such as global change and sustainable use of Earth's resources in urbanizing societies strongly involve the solid Earth. This includes assessing and mitigating risks from various natural and anthropogenic hazards, natural and induced seismicity, volcanic activity, and geomagnetic storms. EPOS-ERIC (European Plate Observing System - European Research Infrastructure Consortium) builds an e-platform providing access to large quantities of European georeferenced data relating to the solid Earth. Nordic EPOS enhances and stimulates the ongoing active Nordic interactions related to Solid Earth RI in general and EPOS in particular. Together we can address global challenges in Norden and with Nordic data. We develop expertise and tools designed to integrate Nordic RI data and to enhance their accessibility and usefulness to the Nordic research community.

Nordic EPOS - A FAIR Nordic EPOS Data Hub - is a consortium of the Nordic geophysical observatories delivering on-line data to EPOS Thematic Core Services. Nordic EPOS consortium comprises the Universities of Helsinki (UH), Bergen (UiB), Uppsala (UU), Oulu (UOULU) and Geological Survey of Denmark and Greenland (GEUS) and Icelandic Meteorological Office (IMO). The hubs' main tasks are to advance the usage of multidisciplinary Solid Earth data sets on scientific and societal problem solving (Figure 2), increase the amount of open, shared homogenized data sets, and increase the scientific expertise in creating sustainable societies in Nordic countries and especially in the Arctic region. In addition to developing services better suited for Nordic interest for EPOS, it will also try to bring forward

\footnotetext{
${ }^{2}$ Nordic EPOS working group: Barsotti S., Dahl-Jensen T., Funck T., Hillers G., Indrøy H.K.S., Keiding M., Kukkonen I., Larsen T.B., Lund B., Michalek J., Oladottir B., Pfeffer M.A., Rinds N., Rønnevik C., Tellefsen K., Vuorinen T., etc.
} 
Nordic research interest, such as research of Arctic areas in TCS and EPOS-ERIC governance and scientific boards.

\section{Nordic EPOS Objectives}

The hub has three main objectives. First is to increase awareness and usage of multi-disciplinary Nordic EPOS data, data products, software and service for scientific and societal problem solving. Second is to increase the amount of, and access to, Nordic FAIR data, and third to support data management of new data types and scientific expertise needed for safe and sustainable societies in Nordic countries and especially in the Arctic region. For the comprehensive list of objectives, see Figure 1.

\section{Nordic EPOS - A FAIR Nordic EPOS data hub}

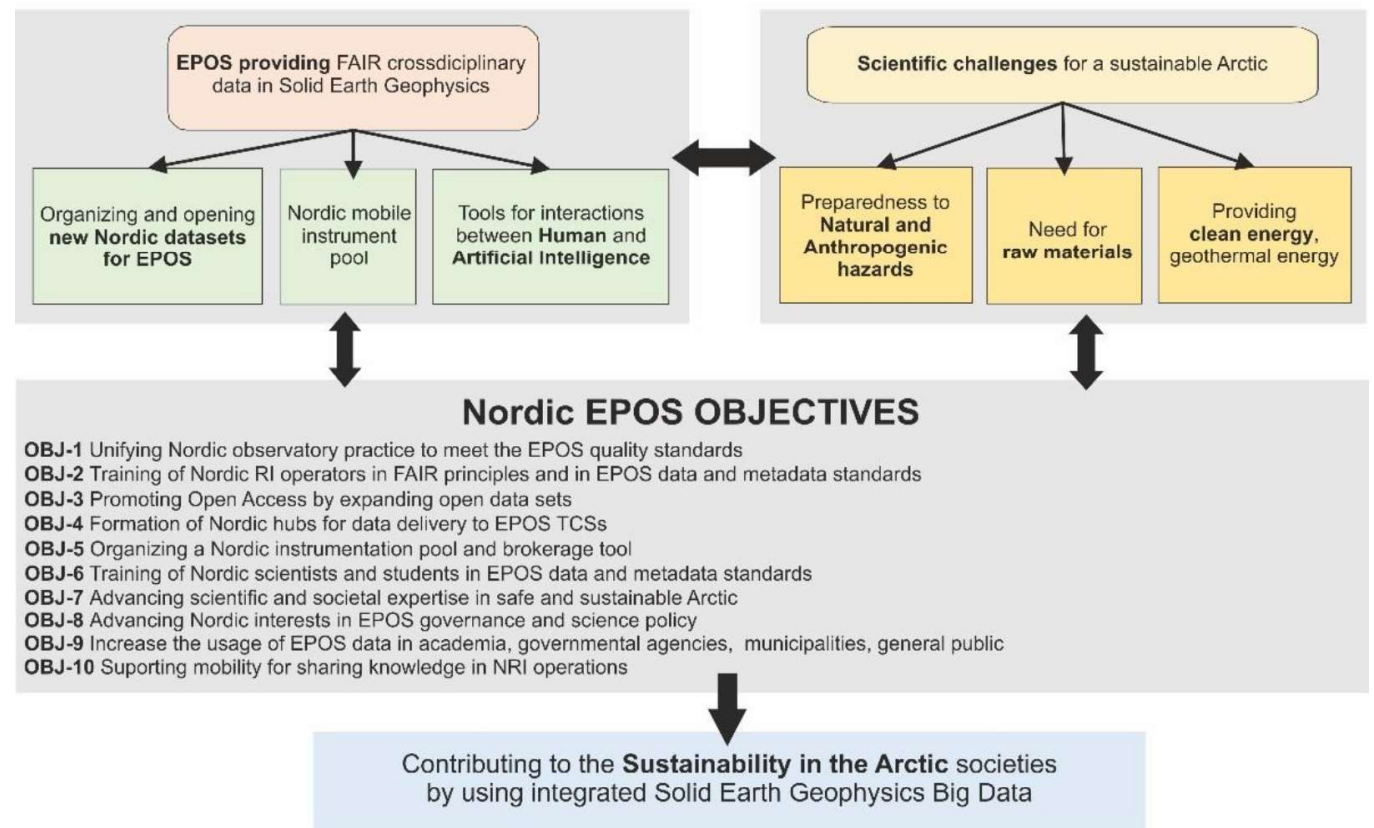

Figure 1. Mission and goals of Nordic EPOS.

\section{Nordic EPOS TASKs and Activities}

To reach the objectives, the Nordic EPOS is organized into Tasks and Activities. The project has six main infrastructure TASKs I-VI and one transversal TASK VII on communication and dissemination. Many of the tasks are addressing several objectives. The TASKs are I - Training in usage of EPOS-RI data and services; II - Nordic data integration and FAIRness; III - Nordic station management of seismological networks, IV - Induced seismicity, safe society; V - Ash and gas monitoring; VI- Geomagnetic hazards; VII - Communication and dissemination. Each of the main partners is responsible for several Activities in one or several TASKs. The activities within the TASKs are workshops, tutorials, demos and actual and virtual training sessions, website and communication and dissemination of EPOS data and metadata information at local, national and international workshops, meetings, conferences. For the comprehensive list of upcoming events, see the Nordic EPOS webpages (https://www.helsinki.fi/en/infrastructures/nordic-epos).

\section{Acknowledgements}

The Nordic EPOS is funded through the NordForsk's call for Nordic Research Infrastructure (RI) Hubs for 20202023. 